\title{
Los salvadoreños evalúan el primer año de gobierno de Flores
}

\author{
Instituto Universitario de Opinión Pública
}

\section{Resumen}

Como es costumbre, a finales del mes de mayo el IUDOP cursó una encuesta de opinión pública para conocer las valoraciones que hacen los salvadoreños sobre el primer año de gobierno de Francisco Flores. La encuesta encontró que los ciudadanos evalúan de forma "regular" el desempeńo de la administración. Aunque, en general, mantienen una percepción positiva de la imagen del presidente, resienten el hecho de que su gobierno no se ha mostrado muy dispuesto a escuchar las demandas de la población y resolver los problemas fundamentales del país, en especial la economía.

\section{Introducción}

En el pasado mes de junio, el tercer gobiemo de ARENA, liderado por Francisco Flores, cumplió su primer año de gestión. Haciendo uso de una práctica ya institucionalizada por el Instituto Universitario de Opinión Pública de la Universidad Centroamericana José Simeón Cañas, se realizó una encuesta a nivel nacional para recoger las percepciones sobre la actuación del Ejecutivo en este primer año.

Los resultados pueden resultar repetitivos en comparación con otras encuestas similares cursadas en los gobiernos anteriores, pero, en esencia, no lo son. Y no lo son porque al hilar un poco fino pueden descubrirse las diferencias entre las visiones que reina- ban hacia un gobierno y otro. Es cierto que se encuentra que los salvadoreños señalan aspectos muy parecidos como logros y como fracasos. Es cierto que cuestiones como la infraestructura del país parece ser una constante en los gobiemos de ARENA, pero ello indica también que en términos de los aspectos positivos, las administraciones de Cristiani, Calderón y Flores no han sabido diferenciarse mucho. La de Flores no parece separarse, pero aún le queda tiempo para hacerlo. También es cierto que lo que los salvadoreños suelen definir como sus principales problemas subsisten como fracasos: delincuencia y economía. Pero no es menos cierto que Flores está siendo valorado no sólo por ello, sino también por un aspecto que él mismo —o su equipo de cam- 
paña presidencial- ayudó a poner en boca de los salvadoreños y que generó expectativas en los mismos: la actitud de estar pendiente y escuchar las demandas de los ciudadanos. Al final, éste parece ser uno de los factores que diferencian la evaluación del tercer presidente arenero de los demás.

Este artículo es una actualización de cómo ven los salvadoreños a su gobierno; por la naturaleza metodológica de la información (las encuestas) puede parecer demasiado parcial e incompleto, pero contribuye a dejar constancia de cómo veían los ciudadanos a este gobierno. El trabajo se divide en varias partes. A continuación de este apartado se presentan los detalles metodológicos, luego vienen los resultados y se presentan de entrada las opiniones sobre el desempeño del gobierno; enseguida se presentan algunas opiniones sobre la figura del presidente, los factores que determinan la evaluación del mismo y algunos datos adicionales.

\section{Metodología}

Entre el 20 y 25 de mayo del 2000 , el Instituto Universitario de Opinión Pública (IUDOP), de la Universidad Centroamericana "José Simeón Cañas" (UCA), realizó una encuesta de opinión, cuyo propósito era conocer la evaluación de los salvadoreños sobre el primer año de gobiemo de Francisco Flo- res, conocer los comentarios de la población sobre el tercer año de las alcaldías y la asamblea legislativa, las expectativas de los ciudadanos sobre la nueva administración y la Asamblea Legislativa entrante y, a la vez, recoger información respecto a los pasados comicios legislativos y municipales. En el presente artículo sólo se abordarán los resultados referentes a la evaluación del primer año de gobierno ejecutivo.

La muestra nacional se diseñó de tal manera que reflejase lo más fielmente posible la totalidad de la población salvadoreña mayor de 18 años, esto según los datos del Censo Nacional de Población de 1992 y del informe disponible de la Encuesta de Hogares de Propósitos Múltiples de la Dirección de Información del Ministerio de Economía de 1996. La cuota muestral incluyó 36 municipios de los catorce departamentos de la República. En cada departamento, la muestra se dividió en dos grandes sectores: urbano y rural. El sector urbano fue dividido en cinco estratos sociales: alto, medio alto, medio bajo, obrero y marginal, mientras que el sector rural se dejó como una categoría aparte por las dificultades de encontrar criterios de tipificación en el campo. En el muestreo se consideraron también cuotas por sexo y edad de los encuestados, de tal manera que cada boleta estaba marcada con las características que debía cumplir el entrevistado para ser considerado en la investigación.

Cuadro 1

Distribución de la población encuestada según departamento y sector social

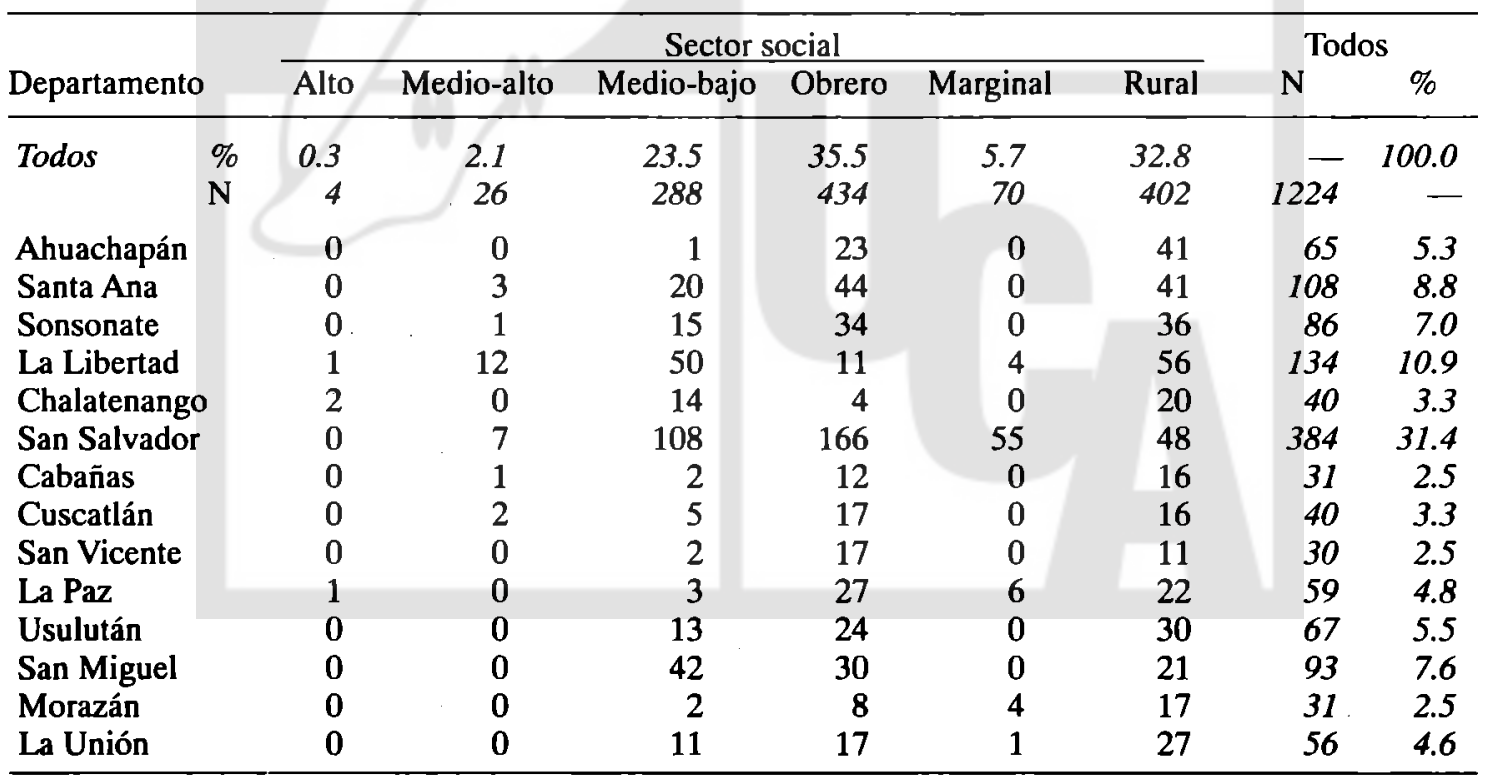


Para el diseño del marco muestral se tomó como base la cartografía censal de la Dirección General de Estadísticas y Censos (DIGESTYC), del Ministerio de Economía de El Salvador. Dicha cartografía está compuesta por 39 mapas y cada uno muestra una zona urbana de 2000 a 15000 viviendas y está dividido en segmentos numerados correlativamente siguiendo una secuencia espiral. Cada uno de los segmentos abarca entre 150 a 400 viviendas. El proceso de selección de los segmentos en donde se aplicaría la encuesta fue sistemático con un punto de arranque aleatorio. Primero se elaboró una lista de los segmentos que contenía cada mapa y luego se procedió a calcular una constante que permitiera seleccionar dichos segmentos. Después se escogió un número al azar, el cual representaría el punto de arranque, y a partir de éste se contabilizaba un número de segmentos equivalente a la constante calculada para lograr determinar el siguiente segmento que se habría de elegir. A partir de este procedimiento se asegura la aleatoriedad en la elección de los segmentos y la dispersión de los mismos, para lograr cubrir representativamente la zona de estudio.

La aplicación del cuestionario se hizo por aproximación no sistemática a los hogares ubicados en los municipios y las zonas definidas aleatoriamente. Los entrevistadores explicaban a las personas abordadas los objetivos y el tema de la encuesta. En cada caso se entrevistó únicamente a personas que quisieran contestar (una persona por hogar) y que cumplieran con los requerimientos descritos en la boleta para completar la cuota muestral.

La muestra final obtenida fue de 1224 encuestas válidas, con un margen de error estimado de $+/-0.04$ (cuatro por ciento). El 47.5 por ciento de los encuestados pertenecían al sexo masculino y el 52.5 por ciento, al femenino. La edad promedio fue 36.9 años y la desviación típica de 14.9 años. Los entrevistados tenían un promedio general 7.8 años de estudio y el 35.3 por ciento manifestó estar empleado formalmente o poseer un trabajo propio.

\section{Evaluación del gobierno}

La encuesta reveló que la mayoría de los ciudadanos no han visto cambios positivos en el país, como producto de la gestión gubemamental del equipo de Francisco Flores luego de su primer año de gestión. Seis de cada diez ciudadanos salvadoreños no han visto transformaciones positivas en el pais, mientras que cuatro de esos diez sí. Aunque no parece haber diferencias muy notables, la percepción de la ausen- cia de cambios positivos es más frecuente en los sectores medio-altos y en los sectores bajos de extracción urbana; de igual manera es una opinión más frecuente entre las personas cuyas edades oscilan entre los 26 y 55 años, entre quienes tienen mayor nivel educativo (técnico o universitario) y entre las personas que no tienen partido de preferencia o que son simpatizantes del FMLN.

En el otro lado de la moneda, la mitad de los salvadoreños - -el 50.6 por ciento-sí han notado cambios negativos frente a, prácticamente, la otra mitad que no ha percibido cambios negativos. Los grupos en donde prevalece la opinión más negativa con respecto a la situación del país son: los residentes del Área Metropolitana de San Salvador, los ciudadanos de sectores medio-bajos y los correligionarios de partidos de oposición ideológica al gobierno como el FMLN y el CDU.

¿Cuáles son, a juicio de los ciudadanos, los logros y los fracasos del gobierno de Francisco Flores luego del primer año de gestión? En el caso de los logros, las respuestas fueron muy diversas, dado que la mayoría de la gente manifestó que no podía identificar logro alguno. Más del 40 por ciento de los salvadoreños sostuvieron que no había logro alguno en términos del trabajo gubernamental y el 17.2 por ciento dijo que no sabía cuáles eran. Eso suma alrededor del 60 por ciento. El resto de ciudadanos se dividió al señalar logros como la infraestructura (15.6 por ciento) -el cual fue el señalado con más frecuencia-, los proyectos comunitarios (4.9 por ciento), la ayuda a pobres (3.8 por ciento), la disminución de la delincuencia (3.8 por ciento) y la inversión extranjera ( 2 por ciento), entre otros aspectos citados menos frecuentemente.

\section{Cuadro 2}

Percepción de cambios positivos y negativos en el país desde que entró el gobierno de Flores (En porcentajes)

\begin{tabular}{lcc}
\hline & \multicolumn{2}{c}{ Cambios en el país } \\
Respuesta & Positivos & Negativos \\
\hline Sí & 37.1 & 50.6 \\
No & 61.8 & 47.9 \\
No sabe & 1.1 & 1.6 \\
\hline
\end{tabular}

¿Ha notado usted algún cambio positivo en el país desde que entró Francisco Flores como presidente?

¿Ha notado usted algún cambio negativo en el país desde que entró Francisco Flores como presidente? 
A diferencia de las evaluaciones finales del gobierno de Calderón Sol, el tercer gobierno de ARENA no concentra las opiniones sobre logros en el ámbito de la infraestructura. Aunque este se sigue reconociendo como un punto positivo a favor del gobierno actual, está claro que el énfasis del mismo, al menos en este primer año de trabajo, es producto de la inercia de la opinión pública con respecto al gobierno anterior. Tampoco está en lo que podría considerarse como el mayor logro obtenido justo al momento de cumplir su primer aniversario: el TLC con México y el proyecto del corredor interoceánico entre Guatemala, El Salvador y Nicaragua.

Cuando se trata de identificar los fracasos del gobierno, las respuestas no son aún más numerosas; además de que la dificultad para identificar fracaso alguno es, en este caso, mucho mayor. Un poco más del 20 por ciento de los salvadoreños no supieron identificar un fracaso importante del gobierno ejecutivo de Francisco Flores luego de un año de labores; mientras otro porcentaje similar (el 19.4 por ciento) sostuvo que no hay fracasos importantes en esta gestión gubernamental. El resto de personas, un poco menos del 60 por ciento, identificaron los siguientes aspectos como fracasos del gobierno: el incremento del IVA' (11.9 por ciento), mal gobierno (8.6 por ciento), alza de los precios (6.1 por ciento), delincuencia (5.3 por ciento), pobreza ( 4.3 por ciento), desempleo (4 por ciento), problemas en el Seguro Social (3.8 por ciento), huelgas y conflictos laborales (3.7 por ciento) y problemas económicos (3.2 por ciento), entre otros fracasos.

Aunque las respuestas son diversas y cada una fue citada por un pequeño porcentaje de personas, las mismas parecen ir orientadas hacia grandes temas de preocupación ciudadana. El tema del IVA y el alza de los precios tiene que ver con la inquietud acerca de la capacidad económica de los ciudadanos y esto, a su vez, está relacionado con el señalamiento de la pobreza, el desempleo y los problemas económicos. Por último, casi el 30 por ciento de los ciudadanos señalan aspectos económicos como el prin- cipal fracaso del gobierno de Flores, luego de su primer aniversario de trabajo. Además, los conflictos laborales aparecen como otra área conflictiva en el desempeño del gobiemo para los ciudadanos; los problemas de huelgas, especialmente las relacionadas con el Seguro Social, hicieron mella en la imagen del gobierno y eso parece haber tenido un impacto no sólo en la imagen del mismo, sino también en el desempeño del partido gobernante en las pasadas elecciones municipales y legislativas (Cruz, 2000).

Esto provoca que, a pesar de que los ciudadanos estén más dispuestos a enumerar distintas fallas del gobierno, el sentido de las mismas es menos dispersa y diversa que en el caso de los logros. En el caso de los logros, los salvadoreños dividían más el sentido de los mismos en sus respuestas; infraestructura, ayuda a pobres, disminución de la delincuencia, inversión extranjera y ayuda al sector agrícola son temas que difícilmente pueden ser englobados en un gran tema; en cambio, los fracasos sí suelen apuntar a dos grandes temas: lo económico y el manejo de los conflictos sociales.

Lo anterior tiene que ver con la opinión, sostenida por más de la mitad de los ciudadanos, de que la situación económica del país ha empeorado desde que entró el actual gobierno. El 56.7 por ciento de los consultados por la pesquisa del IUDOP sostuvieron esa opinión, frente a un 28.5 por ciento que cree que sigue igual y sólo un 13.7 por ciento que considera que la situación económica ha mejorado. $\mathrm{Y}$ es que la encuesta realizada por la UCA sugiere que esta es una de las áreas más problemáticas con respecto a la gestión de Francisco Flores. Dos de cada tres salvadoreños se mostraron en desacuerdo con la política económica impulsada por el actual gobierno, en tanto que el resto se dividía entre los que decían estar de acuerdo y los que no sabían. La oposición a la política económica impulsada por el actual gobierno es más fuerte en los habitantes del Área Metropolitana de San Salvador, entre los sectores medios y bajos urbanos, entre las personas que tie-

1. En realidad, no se trata de un incremento del impuesto al valor agragado, sino el levantamiento de la exención del mismo para los productos de la canasta básica y medicinales. 
nen mayor nivel de educación y entre los seguidores de los partidos de oposición.

\section{Figura 1}

\section{Opinión sobre la política económica impulsada} por el actual gobierno

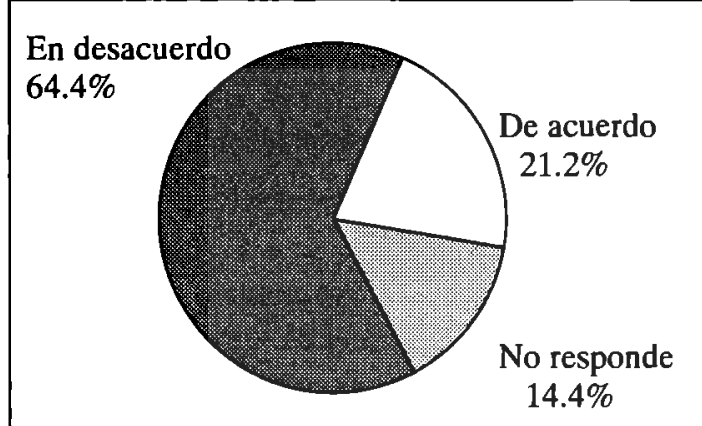

¿Está usted de acuerdo o en desacuerdo con la política económica impulsada por el actual gobierno?

Una de las principales razones para adversar la política económica del gobierno, luego de un año de trabajo, tiene que ver con el anuncio del presidente de levantar la exención de aplicación de impuestos a los productos básicos alimenticios y medicinales. Así lo consigna el sondeo mismo. De acuerdo con la mayoría de los ciudadanos consultados, la aplicación del impuesto sobre el valor agregado no mejorará la economía del país y sólo el 13.4 por ciento considera que sí se verá favorecida por la aplicación de dicho impuesto. Los que menos adversan la aplicación del impuesto son personas que pertenecen a los sectores socioeconómicamente más altos.

Ahora bien, la otra área de gobernabilidad que parece haberle complicado la gestión al gobierno es la relación con los conflictos laborales. Casi el 57 por ciento de los ciudadanos no estuvieron de acuerdo con la manera en que el gobierno manejó el conflicto del Seguro Social. Esto es especialmente cierto en el caso de los salvadoreños que viven en el Área Metropolitana de San Salvador, quienes pertenecen a las clases medias, aquellos que poseen un elevado nivel de educación y los que suelen votar por los partidos de oposición. En el otro lado de la moneda, el gobierno recibió el respaldo de un poco más de la cuarta parte de los ciudadanos (26.9 por ciento) por su manejo del conflicto del Seguro y entre quienes más lo apoyaron están los residentes de la zona paracentral del país, las personas con edades mayores a los 55 años, quienes han estudiado hasta plan básico y los electores del partido en el gobierno.

La mayoría de ciudadanos consultados, aunque con menos unanimidad que en el caso anterior, estuvieron de acuerdo con una solución que implicaba la recontratación de los trabajadores despedidos a causa de la huelga. De acuerdo con las cifras, más del 60 por ciento consideró que el gobierno debía restituir a los trabajadores del Seguro Social ${ }^{2}$ y el 29 por ciento se opuso a esa medida; el resto prefirió no emitir opinión alguna.

Al momento de cursar la encuesta, no toda la gente parecía estar muy segura de que las negociaciones entre el gobierno y los trabajadores encontraran una resolución al conflicto. Mientras que el 44.1 por ciento de los ciudadanos salvadoreños pensaban que tales negociaciones resolverían el conflicto, un porcentaje menor pero importante (el 39.3 por ciento) sostenía que no podrían solucionarlo. En este caso, las personas con mejores condiciones socioeconómicas y educativas se mostraban más cautelosas que el resto.

Por último, la otra área particularmente sensible -al revisar el listado de los problemas del país identificados por la ciudadanía - es el área de la seguridad pública. El tema del combate a lo que constituye el problema del país más frecuentemente citado no sólo apareció mencionado como logro del gobierno por un pequeño grupo de ciudadanos, también apareció señalado como fracaso por otro pequeño grupo de salvadoreños ${ }^{3}$. En todo caso, el tema constituye una de las áreas más delicadas de la gestión gubernamental, dado su impacto en la percepción de seguridad de la población. Los resultados de la encuesta en esta área dejan también un balance negativo del trabajo del gobierno. Un poco más de la mitad de los salvadoreños (el 53.2 por ciento) cree que la delincuencia ha aumentado con el actual gobierno, en tanto que la otra mitad se divide al opinar que la delincuencia continúa con la misma intensidad (25.4 por ciento) y que la criminalidad ha disminuido (21.4 por ciento).

2. Lo cual terminó haciendo al final, pero bajo ciertas condicioncs.

3. Sin embargo, los porcentajes eran tan bajos que las diferencias numéricas entre ambos son irrelevantes. 


\section{Cuadro 3 \\ Opinión sobre si el Plan de Seguridad Pública está dando resultados \\ (En porcentajes)}

\begin{tabular}{lrrrrr}
\hline & \multicolumn{5}{c}{ ¿Está dando resultados? } \\
Situación de delincuencia & Mucho & Algo & Poco & Nada & Ns \\
\hline Todos & 12.5 & 30.4 & 42.0 & 13.0 & 2.0 \\
Ha disminuido & 33.0 & 35.2 & 27.2 & 3.1 & 1.5 \\
Sigue igual & 11.3 & 32.9 & 43.5 & 10.0 & 2.3 \\
Ha aumentado & 4.9 & 27.2 & 47.2 & 18.5 & 2.2 \\
\hline
\end{tabular}

¿Qué tanto cree usted que el nuevo plan de seguridad pública está dando resultados?

Lo anterior tiene que ver con la opinión de que el nuevo plan de seguridad pública, anunciado e implementado por el actual gobierno, no está dando los resultados esperados por la población. Sólo el 12.6 por ciento de la gente considera que el plan está dando muchos resultados, mientras que el 30.3 por ciento cree que en "algo" ha dado resultados. El 41.9 por ciento piensa que ha dado pocos resultados y el 13 por ciento no ve ningún resultado. Aunque estos resultados no son muy favorables e inciden en la manera en que la gente evalúa el avance de la criminalidad en el país, un análisis comparativo con sondeos anteriores muestra que las opiniones se han vuelto levemente más positivas a favor del gobierno. Al cumplir los primeros cien días de gestión, las opiniones se concentraban más en decir que no había resultado alguno; ahora, sin embargo, esa opinión ha disminuido. En todo caso, la percepción sobre la situación de seguridad pública está profundamente vinculada con la opinión sobre qué tanto ha hecho el gobierno para combatir la delincuencia. Y en eso los porcentajes de aprobación del trabajo gubernamental siguen siendo muy bajos.

Un tema de particular importancia en la gestión presidencial de Flores es el de su relación con los ciudadanos. Este aspecto fue particularmente puesto sobre el tapete, dada la orientación que el ahora presidente y su equipo dieron a la campaña publicitaria que los llevó a ser la opción ganadora en las elecciones de 1999. En concreto, Flores prometió, como eje de su gestión, un trabajo basado en la atención a las demandas populares, un trabajo cimentado en "escuchar a la población". La evaluación de los primeros cien días de gestión, en septiembre de 1999 , demostró que una de las cosas que más seguía esperando la población era precisamente esa conduc- ta de escuchar las demandas ciudadanas. En julio del año 2000 , más del 60 por ciento de la gente cree que el gobierno actual ha escuchado poco o nada las demandas de la población, en tanto que el 30 por ciento restante tiene opiniones divididas y consideran que el gobierno ha escuchado "algo" o mucho las demandas ciudadanas. Las personas que se sienten más escuchadas por el gobierno son aquellas que pertenecen a los sectores socioeconómicamente más altos, los que viven en las zonas rurales del país y quienes tienen un menor nivel educativo.

Figura 2

¿Qué tanto cree que el gobierno ha escuchado las demandas de la gente?

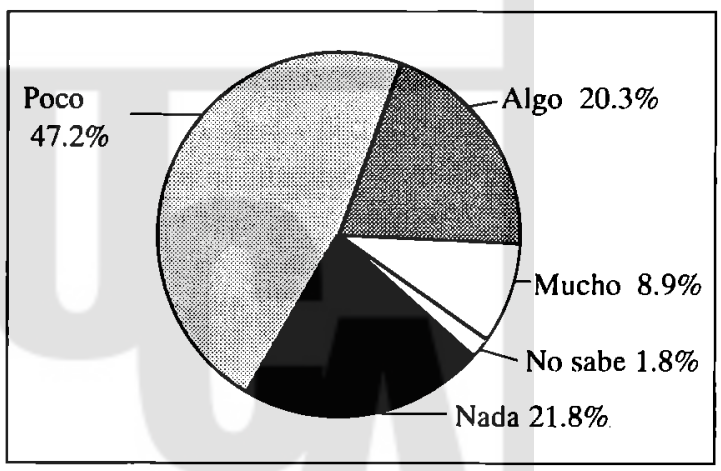

Esto tiene que ver con la percepción de cuál es el grupo más beneficiado por las políticas impulsadas por el gobierno. La tercera parte de los ciudadanos piensan que el conjunto de ciudadanos más favorecidos por la preocupación del gobierno son "los ricos", esto lo dice el 36.4 por ciento y, sobre todo, lo 
dicen personas que viven en la zona metropolitana de San Salvador y aquéllos que forman parte del sector marginal de las ciudades; el 21.9 por ciento considera que el gobiemo se preocupa por todos los ciudadanos, lo cual constituye una opinión más frecuente entre las personas con poca formación educativa; otro porcentaje similar -el 21.3 por ciento- apunta a que el gobierno sólo se preocupa por sus propios integrantes, es decir, por ellos mismos; luego, el 8.2 por ciento cree que los más beneficiados son los empresarios y el resto de personas señaló a otros grupos (el partido ARENA, los pobres, etc.). Al final, la

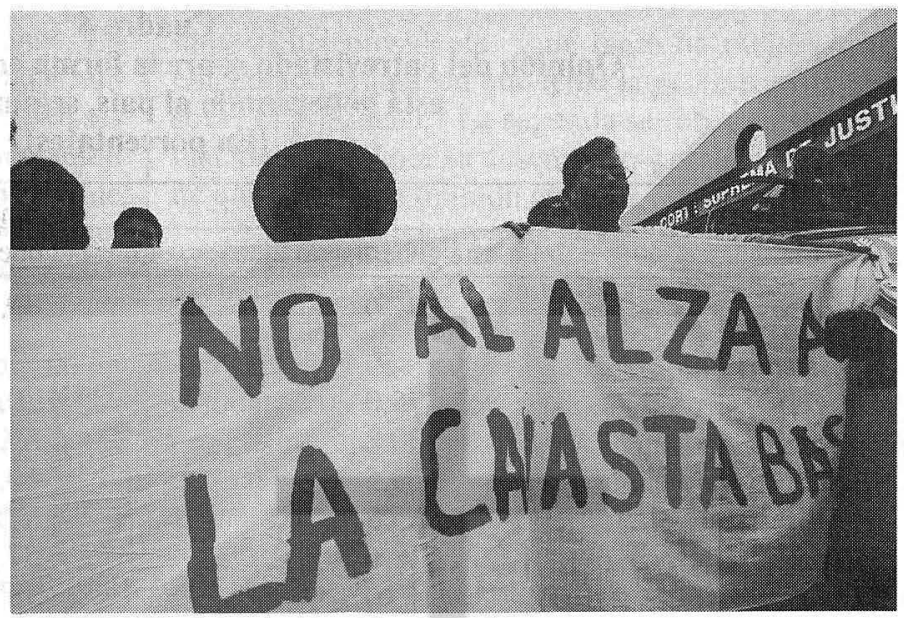
mayoría de la gente considera que el gobierno se preocupa sólo por grupos específicos y no por todos los ciudadanos. Si se suman los porcentajes de las personas que señalan a "los ricos", "ellos mismos", los empresarios y los areneros, se tiene que más del 60 por ciento considera que los más beneficiados son las personas con ventajas económicas y las personas vinculadas al gobierno.

El tema de las demandas ciudadanas y la percepción de quién reúne más atención por parte del gobiemo, también está fuertemente comprometido con la percepción sobre el cumplimiento de promesas por parte del gobierno. El sondeo de la UCA reveló que casi la mitad de los consultados (44.4 por ciento) creen que el gobierno está cumpliendo con algunas de las promesas, el 6.4 por ciento considera que está cumpliendo con todas las promesas y el 47 por ciento siente que la administración Flores no ha cumplido con promesa alguna. En este caso, el balance parece ser más positivo en comparación con otras opiniones y, sobre todo, en comparación con el pasado. En la pesquisa de evaluación de los primeros cien días de gobierno, más del 60 por ciento de los abordados sostuvo que el nuevo gobierno no estaba cumpliendo con sus promesas. En la actualidad, el porcentaje que comparte esa opinión, más del 20 por ciento de la gente, ahora piensa que el Ejecutivo, al menos, está cumpliendo con algunas promesas.

Visto todo lo anterior, ¿cuál es el balance general que hacen los ciudadanos de la actuación del gobierno de Flores? Los resultados del sondeo indican

que las opiniones están relativamente divididas. Mientras la mitad de los salvadoreños piensan que la administración Flores está conduciendo mal al país, la otra mitad sostiene que el país está siendo bien gobernado o que está siendo dirigido de forma "regular" —o se abstuvieron de responder a la pregunta-.

Las opiniones de que Flores y su gabinete están conduciendo bien al país, como puede verse en el Cuadro 4 , son más frecuentes entre la gente de clase alta y entre quienes habitan en la zona rural del país. Además, las valoraciones positivas acerca de la conducción del gobierno aparecen más en la medida en que la gente dispone de menos formación educativa y, finalmente, los areneros y los simpatizantes del Partido Demócrata Cristiano valoran de forma positiva el trabajo del gobierno que el resto de seguidores de los demás partidos políticos.

Lo anterior hace que el trabajo general del gobierno sea calificado como regular por la mayoría de salvadoreños. Efectivamente, la encuesta les pidió que calificaran la actuación de la administración Flores, como lo ha hecho siempre cuando se trata del gobierno, usando una escala similar a la escolar: de 0 a 10 puntos. La nota promedio asignada fue de 5.41 puntos, lo cual lo deja en el área intermedia de calificaciones ${ }^{4}$ y muestra que, aunque podría haber recibido una calificación inferior, el gobierno tiene dificultades para beneficiarse de la aprobación de los ciudadanos por su labor en un año. Con todo, el exa-

4. Aunque si se considera el criterio académico de seis como calificación mínima para aprobar asignaturas, está claro que el tercer gobierno de ARENA no es aprobado por su gestión. 


\section{Cuadro 4}

Opinión del entrevistado sobre la forma en que Francisco Flores

está gobernando al país, según variables

(En porcentajes)

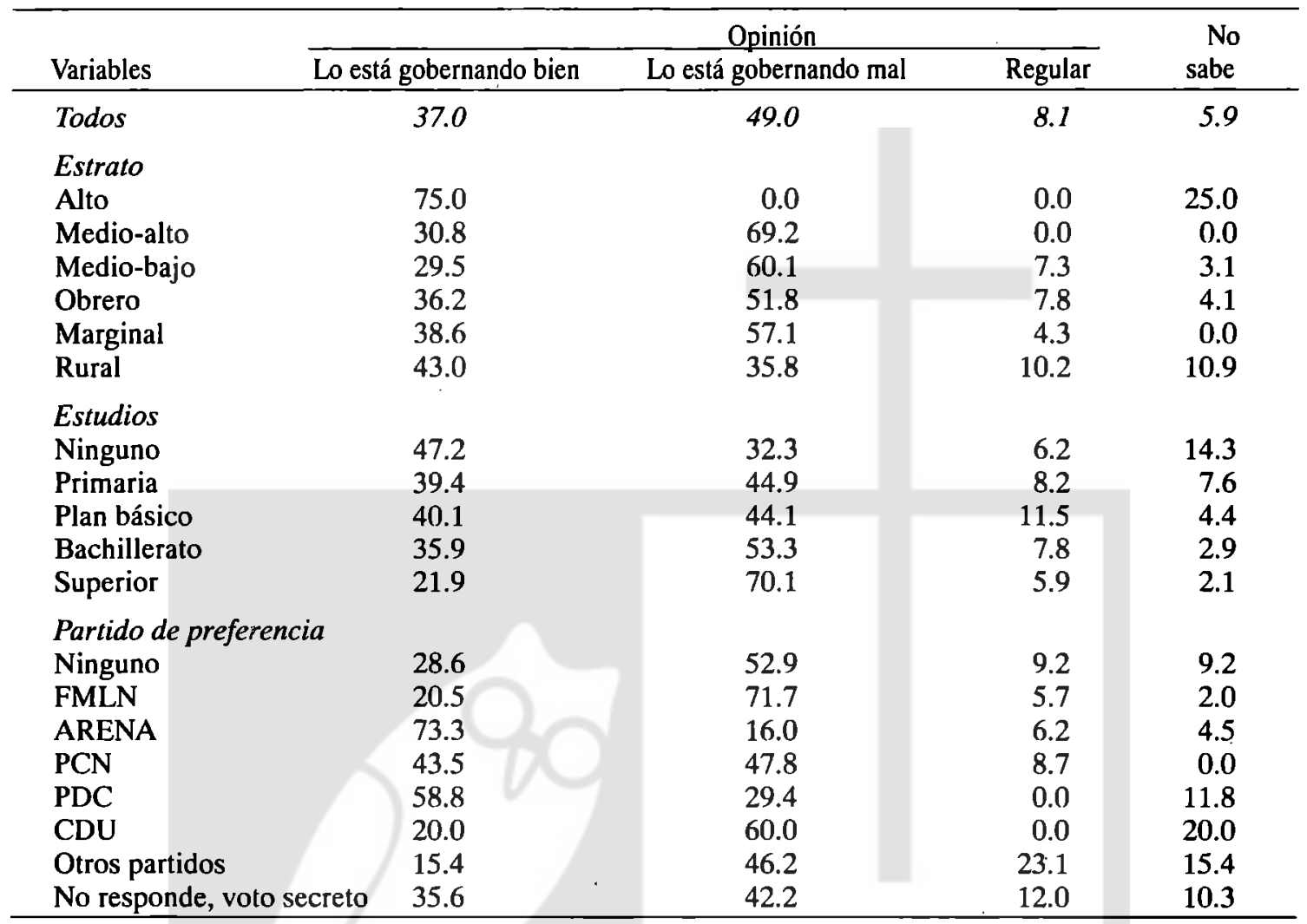

En su opinión, ¿Francisco Flores está gobernando bien al país o lo está gobernando mal?

men -en perspectiva de las calificaciones otorgadas al gobierno en su corta historia - sugiere que para el momento en que fue realizada la encuesta, éste habría recuperado levemente su imagen frente al público, sobre todo después de la bajísima calificación otorgada a la administración Flores en las vísperas de las elecciones. De acuerdo con la serie de encuestas del IUDOP, el gobierno de Francisco Flores habría mejorado su labor en comparación con los resultados obtenidos en febrero del 2000 , pero no habría recuperado aún siquiera los niveles que tenía para diciembre de 1999.
Figura 3

El gobierno de Flores en la perspectiva de la opinión pública

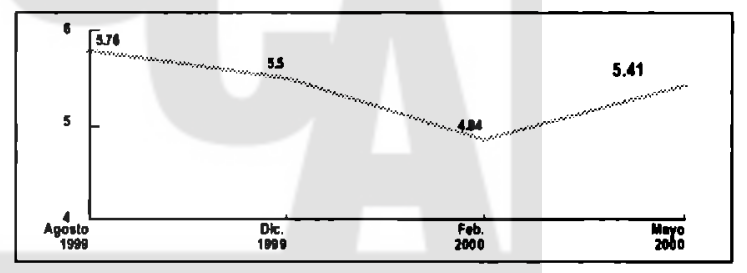

En una escala de 0 a 10 , ¿qué nota le daría al gobierno de Francisco Flores por su desempeño? 
Lo anterior podría deberse a varios hechos. En primer lugar, a la resolución - para esas fechas aún transitoria- del conflicto del Seguro Social; en segundo lugar, a los logros en términos de integración comercial centroamericana, que fue extensamente publicitado; y, obviamente, al fin de la campaña electoral, lo cual estaba desgastando la imagen del partido gobernante.

Ahora bien, lo anterior se refiere al gobierno en su conjunto, pero en ellos desempeña una función especial la percepción que se tiene sobre la actuación de la cabeza, en este caso, el presidente. Antes de ver cómo perciben los salvadoreños al mandatario personalmente, es importante presentar los resultados que indican cuál es la secretaría que goza del mayor y del menor beneplácito de la población. Según las respuestas de los ciudadanos, los ministerios cuyo trabajo se ha destacado son: Educación (17.9 por ciento), Salud (7.8 por ciento), Obras Públicas $(7.6$ por ciento) y Justicia y Seguri-

... la encuesta les pidió [a los salvadoreños] que calificaran

la actuación de la administración Flores, como lo han hecho siempre cuando

se trata del gobierno, usando

una escala similar a la escolar:

de 0 a 10 puntos. La nota

promedio asignada fue de 5.41 puntos. imagen del presidente, ¿qué tanto ha mejorado o uación general por su desempeño y obviamente tie-

En principio, los resultados muestran que la mayoría de la gente no ha modificado la imagen que presidente. Más del 50 por ciento de los mandatario salvadoreño se mantenía igual; el 21.7 por ciento dijo que su imagen había mejorado y la opinión del 25.2 por ciento la enfocó en el lado negativo del espectro. Quienes más modificaron la imagen del presidente fueron las personas de los sectores medio-altos. De acuerdo con las cifras, más del 57 por ciento de esta gente sostuvo que su opinión sobre Francisco Flores había empeorado. El resto de grupo sociales no presentaron diferencias significativas en las opiniones.

En términos de su trabajo como jefe del Ejecutivo, los resultados parecen favorecerle un poco más, inclusive están por encima de la evaluación del gobierno. El 42.5 por ciento de los salvadoreños calificó como bueno o muy bueno el desempeño del presidente; en tanto que el 31.5 por ciento lo evaluó como regular y el 24.2 por ciento lo situó como malo o muy malo. El presidente recibe las calificaciones más positivas de la gente que vive en la zona paracentral del país, de las personas más jóvenes, de la gente que ha estudiado hasta bachillerato y de los correligionarios del partido ARENA. En contraparte, el gobemante recibe las calificaciones más bajas de aquéllos que viven en San Salvador, de las clases medias, de las personas con mayor nivel educativo y de los simpatizantes del partido FMLN.

Sin embargo, un dato que dice mucho de la forma en que es percibido el presidente es el que revela que el 58.5 por ciento de los ciudadanos creen que el mandatario no tiene control sobre las decisiones del gobierno. Esto frente a un 25 por ciento que sí lo ve como responsable de las decisiones gubernamentales y un poco más del 16 por ciento que prefirió no 
opinar. Esta forma de opinar parece estar muy relacionada con la evaluación que se hace del mandatario. En la medida en que la gente piensa que el jefe del Ejecutivo no está a cargo de las decisiones fundamentales del mismo, en esa medida tiende a evaluar de peor manera la actuación del mandatario. Por el contrario, las personas que consideran que él es quien toma las decisiones gubernamentales, en esa medida tienden a valorar de forma positiva su mandato. Aun así, hay un importante segmento de la población que evalúa positivamente al mandatario, pero que no lo ve como la persona que toma las decisiones.

\section{Cuadro 5}

Opinión sobre el control de las decisiones del gobierno por parte de Francisco Flores, según evaluación del mismo

(En porcentajes)

\begin{tabular}{|c|c|c|c|c|}
\hline \multirow{2}{*}{$\begin{array}{l}\text { Evaluación del } \\
\text { desempeño del presidente }\end{array}$} & \multicolumn{3}{|c|}{$\begin{array}{l}\text { ¿Tiene F. Flores control sobre } \\
\text { las decisiones del gobierno? }\end{array}$} & \multirow[t]{2}{*}{ Todos } \\
\hline & No & Sí & No sabe & \\
\hline Muy buena & 24.6 & 67.7 & 7.7 & 5.3 \\
\hline Buena & 43.3 & 37.4 & 19.3 & 37.2 \\
\hline Regular & 64.2 & 17.6 & 18.1 & 31.5 \\
\hline Mala & 79.5 & 8.9 & 11.6 & 21.1 \\
\hline Muy mala & 92.1 & 2.6 & 5.3 & 3.1 \\
\hline No sabe & 54.4 & 9.1 & 3.9 & 1.8 \\
\hline Todos & 58.3 & 25.2 & 16.6 & - \\
\hline
\end{tabular}

¿Usted piensa que Francisco Flores tiene control de las decisiones dentro de su gobicrno o está siendo manipulado por otros sectores?

¿Cómo evalúa là actuación del presidente Francisco Flores en el gobierno, muy buena, buena, mala o muy mala?

\section{Los factores asociados a la evaluación pública del gobierno}

¿Cuáles son los aspectos que la gente toma en cuenta a la hora de calificar el desempeño de la administración Flores en su primer aniversario? Ya se ha visto que varios aspectos de la opinión pública parecen estar relacionados con la forma en que la gente percibe el desempeño del gobierno y todos tienen que ver con el veredicto final que constituye el promedio de nota. Pero entre todo eso no se sabe cuál es el factor que tiene más peso a la hora de evaluar el desempeño del gobierno. La encuesta del IUDOP no ofrece muchas facetas específicas, pero cuenta con las que suelen estar más frecuentemente en la opinión ciudadana y en los debates públicos.

De acuerdo con una regresión lineal realizada para tal fin y tomando la variable de calificación de 0 a 10 como variable independiente, los resultados mostraron que las variables que mejor explican la nota que los ciudadanos han puesto al gobiemo en su primer aniversario son cinco, en orden de mayor a menor importancia: la opinión sobre qué tanto el gobierno escucha las demandas de la población, la opinión sobre el cumplimiento de las promesas por parte del Ejecutivo, la valoración sobre la situación económica del país con el actual gobierno, la creencia sobre la efectividad del plan de seguridad pública y, finalmente, la opinión sobre el manejo del conflicto laboral en el Seguro Social. En otras palabras, en la medida en que una persona ha percibido que el gobierno de Francisco Flores se ha preocupado por escuchar las demandas ciudadanas, ha sentido, además, que el gobierno está cumpliendo con sus promesas, y en la medida en que cree que el país está mejorando económicamente con la gestión del gobiemo - aparte de pensar que el plan de seguridad está funcionando y que está de acuerdo con la forma en que se manejó el conflicto del Seguro-, en esa medida habrán más probabilidades de que esa per- 
sona califique positivamente la gestión del gobierno.

Lo anterior significa que, en lo esencial, la calificación que el gobierno se ha ganado luego de trabajar por un año al frente del país, ha dependido de qué tanto ha sabido escuchar las demandas ciudadanas y ha cumplido con las promesas hechas en campaña -que a la sazón constituyen lo mismo-. En el fondo, el gobierno de Francisco Flores sigue cargando con el éxito de la campaña que lo llevó al poder y la gente está a la espera y reclamándole por las promesas y las expectativas que generó durante la misma.
Es curioso cómo aspectos fundamentales para la situación del país, como la economía y la seguridad pública, pueden pasar a segundo plano a la hora de evaluar las políticas públicas si los ciudadanos no perciben una actitud comprometida del gobierno hacia ellos. Con esto no se quiere decir que para la gente los problemas fundamentales del país no son importantes a la hora de considerar el trabajo del gobierno, más bien se quiere llamar la atención sobre la importancia de aquéllos factores que determinan la manera en que el gobierno debe relacionarse con sus habitantes, lo cual otorga legitimidad a la gestión pública.

\section{Cuadro 6}

Regresión múltiple: predictores de la nota promedio de evaluación al gobierno de Flores

\begin{tabular}{lrrrrr}
\hline Variable & B & $\begin{array}{r}\text { Error } \\
\text { std }\end{array}$ & Beta & t & Sig. \\
\hline (Constante) & & & & \\
\hline ¿Está cumpliendo el gobierno con sus promesas? & .839 & .719 & & 8.121 & .000 \\
Situación económica con el actual gobierno & .954 & .116 & .233 & 8.215 & .000 \\
¿Ha escuchado el gobierno las demandas de la población? & -.682 & .098 & -.197 & -6.964 & .000 \\
¿Está dando resultados el nuevo Plan de Seguridad Pública? & .863 & .085 & .296 & 10.185 & .000 \\
¿Está de acuerdo con el manejo conflicto ISSS? & -.522 & .080 & .110 & 3.999 & .000 \\
Sexo & .177 & .147 & -.105 & -3.898 & .000 \\
Edad & $-3.091 E-03$ & .005 & -.035 & 1.400 & .162 \\
Nivel de estudios & $2.575 E-02$ & .019 & .043 & -.628 & .530 \\
Estrato & $3.372 E-02$ & .060 & .016 & .566 & .172 \\
Frecuencia con que lee, ve o escucha noticias en los medios & -.101 & .083 & -.031 & -1.220 & .223 \\
\hline
\end{tabular}

$R^{2}=0.439$

\section{La principal tarea del gobierno}

Visto lo anterior, los ciudadanos expresaron sus expectativas sobre el trabajo del gobierno respecto a los problemas que más los aquejan. Al ser interrogados de forma abierta sobre la principal tarea que debe enfrentar la administración de Francisco Flores en el próximo año de gestión, los consultados mencionaron: la creación de empleos (21.7 por ciento), el combate contra la criminalidad (21.5 por ciento), el mejoramiento de la economía (16.6 por ciento), la lucha contra la pobreza (12.7 por ciento), la atención de las necesidades del pueblo (5.7 por ciento), el cumplimiento de las promesas ( 3.8 por ciento) y el mejoramiento de condiciones de vida y del país, entre otras cosas.

La mayor parte de aspectos mencionados con más frecuencia tienen que ver con la situación económi- ca, casi el 50 por ciento. Como si fuese una costumbre, los salvadoreños insisten a sus gobernantes sobre la necesidad de concentrar gran parte de sus esfuerzos en mejorar las condiciones económicas del país para superar los grandes males que lo siguen aquejando.

\section{A manera de corolario}

Los resultados de la primera evaluación anual del gobierno de Flores indican que aunque la visión sobre él habría mejorado con respecto a las calificaciones de meses atrás, aún no llega a ser positiva y sigue estando en la esfera de lo "regular". La forma en que los ciudadanos ven al gobierno de Francisco Flores sigue estando, sin duda, impregnada de las fuertes expectativas que se formaron los ciudadanos, al menos aquéllos que votaron por él en la campaña 
electoral de hace casi dos años. Los salvadoreños siguen reclamando atención de su gobierno y, sobre todo, esperan que su presidente renueve su actitud de escucharlos como prometió en la campaña electoral. Es interesante hacer notar que la imagen del presidente, aunque un poco desgastada, se mantiene para muchos ciudadanos. De hecho, varios salvadoreños creen que él podría ser un mejor mandatario de lo que es si se le permitiera gobemar como lo ha prometido.

\section{Cuadro 7}

Partido político por el que votaría el entrevistado, según variables (En porcentajes)

\begin{tabular}{|c|c|c|c|c|c|c|c|c|}
\hline \multirow[b]{2}{*}{ Variables } & \multicolumn{7}{|c|}{ Partido político } & \multirow{2}{*}{$\begin{array}{l}\text { No } \\
\text { sabe }\end{array}$} \\
\hline & Ninguno & FMLN & ARENA & PCN & $\overline{P D C}$ & $\mathrm{CDU}$ & $\overline{\text { Otros }}$ & \\
\hline Todos & 9.7 & 37.0 & 19.9 & 1.9 & 1.4 & 0.4 & 1.1 & 28.7 \\
\hline \multicolumn{9}{|l|}{ Estrato } \\
\hline Alto & 50.0 & 0.0 & 25.0 & 25.0 & 0.0 & 0.0 & 0.0 & 0.0 \\
\hline Medio-alto & 19.2 & 53.8 & 15.4 & 0.0 & 0.0 & 0.0 & 0.0 & 11.5 \\
\hline Medio-bajo & 10.1 & 47.9 & 18.1 & 1.7 & 0.7 & 0.3 & 0.7 & 20.5 \\
\hline Obrero & 10.8 & 41.5 & 17.1 & 2.3 & 1.8 & 0.9 & 1.6 & 24.0 \\
\hline Marginal & 5.7 & 48.6 & 17.1 & 4.3 & 5.7 & 0.0 & 0.0 & 18.6 \\
\hline Rural & 8.0 & 21.6 & 24.9 & 1.0 & 0.7 & 0.0 & 1.0 & 42.8 \\
\hline \multicolumn{9}{|l|}{ Estudios } \\
\hline Ninguno & 8.7 & 14.3 & 20.5 & 1.9 & 0.0 & 0.0 & 2.5 & 52.2 \\
\hline Primaria & 9.0 & 26.5 & 25.4 & 2.0 & 2.6 & 0.6 & 0.6 & 33.2 \\
\hline Plan básico & 7.9 & 37.4 & 18.5 & 3.1 & 1.8 & 0.0 & 1.3 & 30.0 \\
\hline Bachillerato & 11.8 & 48.4 & 19.0 & 1.3 & 0.7 & 0.3 & 0.0 & 18.6 \\
\hline Superior & 10.7 & 56.7 & 12.3 & 1.1 & 1.1 & 1.1 & 2.1 & 15.0 \\
\hline
\end{tabular}

Si las elecciones fueran el próximo domingo, ¿por qué partido votaría usted?

Ahora bien, todo lo anterior tiene un corolario de orden político, es decir, tiene un impacto en las comelaciones políticas partidistas que toman lugar a mediados del 2000 , y la forma más clara de verlo es al revisar las opciones partidistas que prevalecieron en la población en el momento en que el gobiemo cumplía su primer año de gestión y apenas tres meses después de la celebración de las elecciones municipales y legislativas del 2000. Los resultados in- dican un balance de fuerzas a favor del FMLN, con una ventaja que prácticamente dobla a ARENA, algo sin precedente en la historia de consultas de opinión. Sin embargo, hay que decir que tras ello pueden estar el efecto de sumarse e identificarse con el ganador después de las elecciones (las cuales obviamente favorecieron más al FMLN) y otros factores más, además de la posible decepción que prevalece en algunos sectores con respecto al gobierno actual. 